$$
y_{0}^{2 m}
$$


Distribuclón del ingreso e incidencia de la pobreza a lo largo del ajuste

Oscar Altimir

Nuevas orientaciones para la gestión pública

Eugenio Lahera

Industrias petroquímica y de máquinas herramientas:

estrategias empresariales

Daniel Chudnovsky, Andrés López y Fernando Porta

Productividad, crecimiento y exportaciones industriales de Brasil

Regis Bonelli

Maquila en el Caribe: la experiencia de Jamaica

Larry Willmore

Elasticidad-precio de las exportaciones agrícolas de Centroamérica

De la inflaclón crónica a la inflación moderada en el Ecuador

Luis I. Jácome Hidalgo

Nuevas estrategias de las empresas transnacionales en la Argentina

Bernardo Kosacoff y Gabriel Bezchinsky

Informalidad y pobreza en América Latina

Guillermo Rosenbluth

Crisis y alternativas en los procesos de regionalización

Sergio Boisier

Una perspectiva cultural de las propuestas de la CEPAL

Fernando Calderón, Martín Hopenhayn y Ernesto Ottone

La CEPAL y el neoliberalismo: entrevista a Fernando Fajnzylber

Orientaciones para los colaboradores de la Revista de la CEPAL

Publicaciones reclentes de la CEPAL 


\begin{tabular}{r|r|r|}
\cline { 2 - 3 } & 179 \\
\hline
\end{tabular}

\title{
Crisis y alternativas en los procesos de regionalización
}

\author{
"Baja la cerviz, fiero sicambro; quema lo \\ que has adorado y adora lo que has quemado." \\ (Palabras del Obispo de Reims a Clodoveo, \\ Rey de los Francos, al bautizarlo en la fe católica.)
}

\section{Sergio Boisier}

Director de Politicas

y Planificación Regional del Instituto Latinoamericano y del Caribe de Planificación Económica y Social (ILPES)
La revolución científica y tecnológica en marcha obliga a idear nuevas formas de región, superando antiguas restricciones de tamaño y contigüidad: la complejidad estructural es ahora el factor crucial. La generación de estructuras regionales en el ámbito nacional y supranacional exige flexibilidad, dados los rápidos cambios en el entorno regional, la globalización de las economías y las exigencias de conformación democrática de las regiones. Aquí se propone una nueva tipología que distingue entre regiones pivotales, correspondientes a las menores unidades de la actual división políticoadministrativa que tengan suficiente complejidad; regiones asociativas, conformadas por la unión política voluntaria entre a lo menos una región pivotal y una o más unidades político-administrativas colindantes, y regiones virtuales, conformadas por acuerdos tácticos entre regiones pivotales o entre regiones asociativas sin que medie contigüidad. A fin de alcanzar la flexibilidad requerida, se propone reemplazar los esfuerzos dirigistas y del centro hacia abajo por iniciativas desde la base social que permitan la configuración regional de territorios contiguos y también no contiguos, incluso de distintos países. La sección I del artículo reseña los escasos resultados de los esfuerzos de regionalización en América Latina durante los últimos cincuenta años y plantea interrogantes fundamentales respecto a la posibilidad de construir la realidad; la sección II examina las características estructurales que deben tenerse en cuenta al definir las regiones (principalmente la complejidad); la sección III propone tres nuevos tipos de regiones, y la sección IV plantea que debe mantenerse vigente la idea de la construcción política y social regional aplicada ahora a las regiones asociativas y virtuales. 


\section{I}

\section{Introducción}

Hay una cierta constancia repetitiva en la organización del territorio a escala global. Para las Naciones Unidas, el mundo está dividido en regiones. (De hecho, sus cinco comisiones económicas regionales, entre ellas la Comisión Económica para América Latina y el Caribe, reflejan una primera gran fragmentación por regiones del globo terráqueo). A su vez, cada una de estas regiones está configurada por un conjunto de países, a modo de subregiones. Y si se hace un ejercicio de focalización, se descubre que cada uno de estos países se fragmenta a su vez también en regiones o en más preteridas divisiones político-administrativas. Esto ha contribuido a una considerable confusión en el uso del término región, el cual, rastreado su origen etimológico, no hace sino denotar un territorio propio de lo real o de la realeza, es decir, un territorio que conlleva la idea de poder político. Desde tal punto de vista, el concepto de región es más propio de una escala geográfica subnacional que de otras mayores.

Hay áreas en el mundo (por ejemplo, ciertos países europeos) en donde la existencia de una regionalidad histórica ha precedido a una institucionalidad regional y la ha generado (las comunidades históricas en España y su papel en el establecimiento de la Constitución Autonómica). Allí, las nuevas regiones, que no hacen sino recoger, formalizar, modernizar e institucionalizar las percepciones colectivas de pertenencia e identidad vinculadas a ciertos territorios y prácticas sociales, encuentran un camino relativamente sencillo para su consolidación política, social y económica; en cierto sentido, nacen siendo sujetos. Por esta y otras razones, dichas regiones son muy funcionales a la globalización en curso. La modernidad no logró desvincular por completo a la sociedad del territorio, no se completó el paso de una forma de regulación basada en una lógica horizontal - la de los territorios - a una lógica vertical -la de los sectores-, como diría Muller (1990). La paradoja reside en que hoy se observa precisamente una vuelta a la territorialidad, de manera que las sociedades con una modernidad incompleta estarían, desde este punto de vista, mejor equi-

$\square \mathrm{El}$ autor agradece las sugerencias de Gladys Zurita. padas para la competencia internacional. Naturalmente, no se trata del regreso a una territorialidad antigua, autárquica, sino a una territorialidad altamente interactiva, como parte de redes .

En otras latitudes, específicamente en América Latina, la situación ha sido inversa, puesto que en general la institucionalidad ha precedido y generado la regionalidad. Esto significa que ha habido actos políticos deliberados para crear (establecer) regiones sin que preexistan elementos históricos, sociológicos, antropológicos o de otro orden que avalen dichos actos, más basados en una racionalidad instrumental que en el reconocimiento de pertenencias e identidades. En estos casos bien se puede decir que tales regiones han nacido como objetos sin transformarse todavía en sujetos.

En la enorme mayoría de los casos, estas construcciones regionales han surgido de la agregación de varias de las unidades preexistentes en la división político-administrativa del país, conjugando una variedad de criterios para ello (Stohr, 1969; Boisier, 1976). Este ejercicio ya tiene en América Latina cuando menos medio siglo, si el recuento comienza con las primeras regiones identificadas como cuencas fluviales, al amparo de la influencia del modelo institucional de la Tennessee Valley Authority.

Pero es a partir de mediados de los años sesenta que la regionalización, como un verdadero proyecto nacional, se establece como una práctica continua, no por ello exitosa. Su fundamento racional se asocia con la teoría de la modernización social, tan en boga por aquellos años. Como lo indica Germani (1964), la teoría de la modernización social -en tanto teoría del paso del subdesarrollo al desarrollo- hacía especial hincapié en que la idea de la falta de integración interna de los países era un escollo para repetir - -en estas latitudes- el sendero de progreso de las economías ya industrializadas. Las deficiencias de integración interna se manifestaban en la carencia o déficit de infraestructura de transportes y comunicaciones, la inexistencia de mercados nacionales (y prevalencia de segmentados mercados regionales) y la falta de un marco político e institucional único y aceptado en todo el territorio. La recomendación emanada de este diagnóstico era 
obvia: se precisaba integración física, integración económica e integración sociopolítica. Para facilitar esta tarea se consideraba conveniente reemplazar la vieja división político-administrativa (que reflejaba una organización del territorio propia del pasado colonial) por una nueva partición territorial: las regiones. Tales regiones cubrirían todo el territorio nacional configurando un verdadero sistema regional. ${ }^{1}$

Un balance de los esfuerzos regionalizadores hecho a comienzos de los años noventa resultaba más bien desolador. Si el criterio de evaluación era el rango constitucional de las regiones, éste sólo se había alcanzado en Chile (a partir de la Constitución de 1980 y su modificación de 1991 y, en especial, a partir de la Ley Orgánica de Gobierno y Administración Regional de 1993), y en Perú, a partir de la Constitución de 1979 y de la Ley de Regionalización de 1987. Formas jurídicamente menos elaboradas de regionalización existían en Colombia desde mediados de los años ochenta y en Venezuela, que exhibía una larga historia de cíclicos intentos de regionalización desde 1968.

Sin embargo, el carácter de comodín que fue asumiendo la palabra región - a la luz de los comentarios iniciales - hizo de la regionalización una expresión corriente en el lenguaje diario, tanto político como técnico, y el término región se acomodó para servir distintas realidades territoriales.

Al momento de escribir estas líneas se percibe en América Latina una suerte de tendencia contrarregionalizadora. ${ }^{2}$ Los ejemplos más relevantes son los siguientes:

i) En Venezuela está en marcha una operación de desmantelamiento de las corporaciones de desarrollo regional y el Estado nacional está acentuando la dimensión estadual de la descentralización, en desmedro de la dimensión regional.

ii) En Colombia está planteada una importante discusión de orden nacional acerca de la naturaleza misma de las actuales regiones y de sus posibles transformaciones a la luz de la normatividad constitucional, en tanto que el gobierno nacional apuesta, aparentemente, a la división en departamentos y municipalidades.

iii) En el Perú, el gobierno ha desmantelado en la práctica toda la arquitectura institucional regional

\footnotetext{
${ }^{1}$ Hay pocos documentos de gobierno en América Latina que reflejen mejor este tipo de propuesta que el publicado por la entonces Oficina de Planificación Nacional de Chile (ODEPLAN, 1968).

${ }_{2}$ Obsérvese bien que no se trata de una tendencia antirregional, en tanto las regiones sean expresiones del mundo real.
}

establecida por la administración de Alan García, ${ }^{3}$ si bien el Proyecto de Constitución votado el 31 de octubre del presente año (capítulo XIV) otorga una segunda oportunidad a la descentralización al asimilar la región al departamento.

iv) En Bolivia, el nuevo gobierno de Sánchez de Losada también busca en la práctica la disolución de las corporaciones de desarrollo regional $\mathrm{y}$, al igual que en otros países, apunta a la creación de departamentos y a la descentralización municipal.

v) En Chile, el caso que podría considerarse como el más consolidado en materia de regionalización, la apertura democrática y el juego electoral están sacando a luz diversos clivajes regionales, tensiones y fuerzas centrífugas. La idea de una regionalización plena (de carácter político) nunca prendió - por razones obvias - en los países federales más tradicionales, con la sola excepción de la Argentina en los años sesenta y setenta.

Tal parece que la realidad preexistente es más fuerte que los intentos de transformar o reconstruir racionalmente y en forma exógena y dirigista la propia realidad. En verdad, los actos iniciales de voluntarismo político para ordenar el territorio requieren de larguísimos períodos para transformarse en realidades sociales y culturales, y aun teniendo presente la velocidad exponencial del transcurso del tiempo social, no parece ser posible esperar la consolidación de regiones creadas como artificios. ${ }^{4}$

Tal vez ha llegado el momento de reconocer que los intentos dirigistas y del centro hacia abajo para configurar regiones mediante el artificio de sumar y agregar unidades de la división político-administrativa, han llegado a un callejón sin salida. Las resistencias son grandes y los entrabamientos pueden hacer perder oportunidades —de inversión, de mercados, de asociación-: aprovechar oportunidades es la única fórmula de triunfo en un mundo competitivo. La competencia no es el sistema que permite triunfar siempre a los más fuertes, sino el sistema que permite el triunfo sistemático de quienes saben aprovechar las oportunidades, es decir, de los más hábiles.

\footnotetext{
${ }^{3}$ Según comentarios recogidos in situ, la injerencia excesiva de los partidos y la politización de los organismos regionales no habría sido ajena a ello.

${ }^{4}$ Hay que recordar que los departamentos de la Francia metropolitana fueron creados por un acto de la Revolución Francesa de una manera casi grotesca desde el punto de vista de su delimitación. Doscientos años más tarde, el departamento es el referente cultural y de identidad de la gente. En Chile, la provincia, artefacto administrativo originado en 1786 , es el referente territorial inmediato.
} 
El posmodernismo ${ }^{5}$ es el convidado de piedra de los intentos de construir regiones con un alto grado de artificialidad inicial. En efecto, las llamadas ideas posmodernas ponen de relieve y valorizan - a veces más allá de lo pertinente - la diversidad, la heterogeneidad y la fragmentación, y con ello reivindican la identidad y lo particular del territorio original y menor (la vuelta a lo local). El posmodernismo es también una suerte de refugio y amparo de las minorías $y$, por lo tanto, es o puede ser un factor democrático, en tanto la democracia afirma el valor de la diversidad dentro de la unidad.

"El problema de hoy en América Latina es cómo armonizar racionalidad sustantiva con racionalidad formal... El tema de la diversidad territorial es central hoy, cuando emerge la nueva realidad de las identidades nacionales. El mundo se universaliza en lo económico, pero a la vez las identidades se empequeñecen, nacen expresiones nacionales... $\mathrm{O}$ sea, ante la incertidumbre de universalizarme, yo me aseguro retornando a lo comunal, a lo local..." Este planteamiento de Vega (1991) resulta del todo pertinente para esta argumentación.

Probablemente una de las características más negativas de la modernidad ha sido la megalomanía fáustica -como seguramente diría Berman (1991)-, con su irresistible tentación de uniformidad y de homogeneización que tan caro costó a los planificado- res regionales de los años sesenta. ${ }^{6}$ De la tragedia de Goethe hay que recordar siempre el crimen de Filemón y Baucis como expresión de esta tentación homegeneizadora. Desde tal punto de vista, el discurso posmoderno resulta extremadamente atractivo. Es, en cierto sentido, más humanista, pero aquí hay que cuidarse de nuevos espejismos.

"El derrumbe del Estado de Bienestar y de las grandes redes sociales de apoyo que lo caracterizaron (gran empresa, gran sindicato, empleo estable y seguridad social colectiva) fortalece lo local como un nuevo territorio de solidaridad", apunta Boisier (1992) al comentar la esencia del microcosmos regional, es decir, las relaciones entre el hombre y el territorio.

En un libro reciente (Drucker, 1992), de manera poco feliz se habla de la vuelta del tribalismo, para denotar un fenómeno bastante más complejo: la reivindicación de lo local, en un contexto en el que, como se ha dicho, hay que pensar globalmente para actuar localmente, $o$ en el que, una vez más, la revolución científica y tecnológica hace que se confunda lo global con lo local.

Es el peligro de la supremacía del individuo y de la vigencia de una especie de anarquismo territorial - como respuesta pendular o dialéctica al totalitarismo y a la homogeneización - lo que se pone en la mira.

\section{II}

\section{Volviendo a lo básico: ¿qué es una región?}

Tenía razón Hilhorst (1980) cuando escribió que aunque muchos parecen concordar en que el concepto de región es una construcción mental que no tiene con-

\footnotetext{
5 Terreno escabroso a más no poder es el posmodernismo. La modernidad o el modernismo, de data natal imprecisa, se apoyó en tres ideas pilares: la razón, la historia y el progreso. Freud, Nietzsche y Heidegger se encargaron de darle a la modernidad una poco cristiana sepultura. El posmodernismo surge en una fecha imprecisa, no ha mucho, cuando la humanidad toma conciencia de que el proyecto "moderno" ya no es válido. El posmodernismo está en la calle y en los círculos intelectuales (Lyotard, Baudrillard, Vattimo). En este trabajo, el concepto de posmodernismo se asocia básicamente a una característica: la fragmentación.

6 Al hablar de los planificadores regionales de los años sesenta no se hace referencia sólo a una época, sino principalmente a un enfoque, lamentablemente todavía vigente en no pocas organizaciones públicas.
}

trapartida en la realidad, para otros continúa siendo una cuestión importante. Esos otros son precisamente las personas humanas que habitan las regiones (lo que parece ser una expresión redundante - persona humana- no lo es por cierto en la antropología tomista-maritainiana, para la cual la "personalidad" del ser humano es el atributo que distingue en él la espiritualidad de la mera individualidad material) y los decisores y formuladores de políticas cuyo campo de acción es el desarrollo regional. ${ }^{7}$ Hilhorst no ofreció una respuesta a la pregunta básica que sirve de título a esta sección y se limitó a sugerir mayores investiga-

\footnotetext{
7 Véase una rápida visión de la antropología cristiana en Caiceo, 1993.
} 
ciones ubicadas fuera del marco del paradigma neoclásico.

El Stanford Research Institute (SRI International, 1990) sostiene que la racionalidad tradicional de las regiones económicas y de muchas juridicciones políticas está siendo rápidamente desplazada por una nueva lógica económica. El concepto de aglomeración regional describe en forma más precisa los patrones económicos contemporáneos que los tradicionales límites políticos. La economía global ha llegado a ser un mosaico de regiones económicas que se despliegan a través de múltiples jurisdicciones políticas. Esta tendencia requerirá, cada vez más, nuevas formas de colaboración entre naciones, estados, condados y ciudades.

El punto central es que la racionalidad regional está cambiando, como lo plantea dicho instituto. Casi todos los cambios contextuales y estructurales en torno al concepto de región se deben al doble impacto de la revolución científica y tecnológica y de la globalización. Esto obliga a pensar de nuevo la idea de región, volver a lo fundamental, pero sin la absurda pretensión de restablecer categorías obsoletas.

Tres conceptos fuertemente ligados a la definición práctica de regiones, y por tanto fuertemente ligados a los intentos de regionalización, han sido los de distancia, fricción del espacio y contigüidad. Estos tres conceptos entraron en una fase de obsolescencia debido a la robotización, la miniaturización y la satelización. La consecuencia inmediata ha sido la brutal reducción de los costos del transporte (terrestre, aéreo y marítimo) y las comunicaciones. El costo de una llamada telefónica intercontinental no tiene nada que ver hoy con la distancia, sino con la intensidad de ocupación del satélite utilizado en ese momento y de las respectivas estructuras tarifarias (que suelen formar parte del área regulada de los mercados). La creciente importancia de las comunicaciones como factor de localización —-frente a factores tradicionalesacuña términos como telecarreteras y telepuertos. De hecho, un bit de información puede producir en una región una operación económica de una cuantía mayor que el embarque de un navío con carga completa de productos tradicionales. Casi toda la construcción intelectual hecha por Walter Isard y sus colaboradores de la Universidad de Pennsylvania bajo el ambicioso título de "ciencia regional", entró, por este hecho, a un callejón sin salida, como premonitoriamente anotó Holland (1976).

En el pasado, el tamaño de las regiones constituía un criterio importante para su definición. Se su- ponía que una región grande, ${ }^{8}$ tenía mejores posibilidades de defenderse de crisis cíclicas originadas en el comercio externo y también mayor poder político. En este último caso se pasaba por alto que el poder depende no del tamaño, sino del control asimétrico de recursos escasos, algunos de los cuales ni siquiera son de naturaleza material.

El tamaño como criterio para establecer regiones también entró en una fase de obsolescencia. Lo que hoy interesa es la complejidad estructural de un territorio organizado. ${ }^{9}$

Drucker (1992) comenta con propiedad que: "Con el dinero y la información convertidos en transnacionales, inclusive unidades muy pequeñas son ahora económicamente viables. Grande o pequeño, todo el mundo tiene igual acceso al dinero y a la información y en los mismos términos. En realidad, los verdaderos 'éxitos sin precedentes' de los últimos treinta años han sido países muy pequeños." Parece lícito reemplazar países por regiones en la frase anterior.

Si el territorio organizado se visualiza como una estructura sistémica, sus dos características más importantes son precisamente su complejidad y su estado final. La complejidad se refiere a: i) la variedad de estructuras internas que es posible identificar en el sistema; ${ }^{10}$ ii) los diferentes niveles de jerarquía a través de los cuales se establecen los mecanismos de retroalimentación y control del sistema, y iii) las articulaciones no lineales presentes en el sistema, que generan estructuras disipativas. ${ }^{11}$ (Por el contrario, un ejemplo típico de articulaciones lineales está dado por los coeficientes técnicos de insumo-producto.) Siendo el territorio organizado un sistema dinámico, su estado final depende de si se trata de un sistema cerrado o abierto. En el primer caso, el estado final conlleva la maximización de la entropía, en tanto que en el segundo, el estado final equivale a la maximización de la sinergia.

\footnotetext{
8 En el doble sentido geográfico y económico. Sin embargo, el tamaño geográfico se suponía limitado convenientemente por la tecnología y los costos de transporte y por sus efectos sobre la presencia del aparato administrativo en toda la región.

El territorio atraviesa por una secuencia de estados: primeramente se trata de territorios naturales, que se transforman en territorios equipados, los que devienen posteriormente en la categoría más compleja de territorios organizados. Respecto al concepto de complejidad, hay que referirse obligadamente a los trabajos del Premio Nobel I. Prigogine.

${ }^{10}$ En este caso dicha variedad alude a estructuras urbanas, productivas, sociales y políticas.

11 Entendidas - haciendo referencia nuevamente a I. Prigoginecomo sistemas dinámicos caóticos que, en forma espontánea, van generando orden a partir del caos.
} 
Desde un punto de vista complementario y recuperando categorías empleadas por Vapñarsky (1969), la complejidad estructural de un territorio organizado, visto como estructura sistémica, puede medirse mediante los atributos de interdependencia y cerramiento. La complejidad estructural se caracterizaría por una alta interdependencia y un bajo cerramiento. ${ }^{12}$ Está por construirse una ciencia de la economía compleja o una teoría económica de la complejidad, que serviría como marco conceptual y que tal vez proveería el instrumental para trabajar el tema de manera más concreta y operacional.

Así pues, hoy la búsqueda no apunta a determinar cuán grande debe ser una región; más bien, y por el contrario, lo que interesa es identificar el territorio organizado de menor tamaño que simultáneamente presente una elevada complejidad estructural. Por razones de conveniencia práctica, esta búsqueda "hacia abajo" debe limitar con la división político-administrativa vigente (precisamente lo que se quería eliminar veinte años atrás).

En otro plano, la cultura y la identidad asociadas al territorio hoy se revitalizan, no sólo como valores intrínsecos, sino como factores de competitividad regional. Los territorios organizados son los nuevos actores de la competencia internacional por capital, por tecnología y por nichos de mercado. Tales territorios -en tanto regiones- deben proyectarse a sí mismos como una unidad con identidad reconocida, como una totalidad diferenciada, capaz de ofrecer una imagen corporativa en el mejor sentido del término. Esto resulta posible sólo si la región es capaz de generar un proyecto socialmente concertado de región, que no es otra cosa que un verdadero proyecto político generador de una movilización social. Muchas veces ello no será posible si el proyecto político no se acompaña y articula con un proyecto cultural que genere o refuerce la identidad de la comunidad con su propio hábitat regional. ${ }^{13}$

Aunque muchos se resisten a emplear el término "marketing regional", en realidad una nueva e importante función en la gestión contemporánea del desarrollo regional consiste precisamente en la promoción de la región en los mercados externos. La adecuada combinación de endogeneidad y exogenei-

\footnotetext{
12 La interdependencia se refiere a la proporción de interacciones reales o efectivas con respecto al total téorico, y el cerramiento se refiere a la proporción de interacciones que son completadas dentro del sistema.

${ }^{13}$ Véase una argumentación en detalle acerca de proyectos políticos y culturales regionales en Boisier, 1992.
}

dad, clave del desarrollo regional exitoso, se basa en parte en la calidad de esa promoción, en tanto que el capital transnacional moderno considera el entorno territorial (percepción colectiva, identificación, consensualidad) como un factor estratégico para su localización. ${ }^{14}$

La flexibilidad, la elasticidad y la maleabilidad son requisitos indispensables de toda región moderna, en cuanto ellos son factores que facilitan la entrada de las regiones en las redes y su salida de ellas, con velocidad y oportunidad.

La flexibilidad puede facilitarse mediante normativas, incluso constitucionales, que permitan la asociación territorial a partir de la voluntad política de las partes. Indiscutiblemente, esto tiene mucho que ver con el carácter democrático de las regiones. En este sentido es importante hacer referencia a las constituciones de Colombia y del Perú. En la de Colombia, el artículo 306 establece que "Dos o más departamentos podrán constituírse en regiones administrativas y de planificación, con personería jurídica, autonomía y patrimonio propio. Su objeto principal será el desarrollo económico y social del respectivo territorio", y el artículo 307 señala que "La respectiva ley orgánica, previo concepto de la Comisión de Ordenamiento Territorial, establecerá las condiciones para solicitar la conversión de la Región en entidad territorial. La decisión tomada por el Congreso se someterá en cada caso a referendo de los ciudadanos de los departamentos interesados...". En la Constitución del Perú (sometida a referendo el 31 de octubre de 1993) el artículo 190 dice: "Las Regiones se constituyen por iniciativa y mandato de las poblaciones pertenecientes a uno o más departamentos colindantes. Las provincias y los distritos contiguos pueden asimismo integrarse o cambiar de circunscripción...".

La elasticidad y la maleabilidad de las regiones son aquellas condiciones estructurales que les permiten adaptarse al entorno, sea absorbiendo elementos exógenos, sea adecuando su tamaño a las condiciones del medio. Estas dos características se contraponen a la rigidez de las estructuras regionales del pasado.

\footnotetext{
14 La importancia de la identidad regional como factor de desarrolo regional en la Argentina se destaca en Colantuono (1991) y Palermo (1988).
} 
III

\title{
De la región pivotal a la asociativa
}

\author{
y de allí a la virtual
}

Teniendo en cuenta las características que hoy interesan como atributos de las regiones, sugiero llamar regiones pivotales a los territorios organizados, complejos e identificables a la escala de la división políticoadministrativa histórica. Estas regiones pivotales serán provincias en algunos países, departamentos en otros y estados en algunos países federales. En todos los casos son las menores unidades político-administrativas que al mismo tiempo son estructuralmente complejas, poseen cultura e identidad y tienen flexibilidad. ${ }^{15}$

Estas regiones pivotales (que se parecen algo a las core regions de John Friedmann, pero que no son necesariamente de carácter metropolitano) pueden formar regiones de mayor amplitud -regiones asociativas- a partir de la unión voluntaria con unidades territoriales adyacentes. Esto es exactamente lo que se plantea en las constituciones de Colombia y del Perú; si bien en la Constitución colombiana no se hace mención explícita a la contigüidad, ello parece derivarse del texto del artículo cuarto del Proyecto de Ley 184 de 1992, al establecer que la región administrativa y de planificación será "una división del territorio para el cumplimiento de funciones nacionales de planificación". En el caso del Perú -como se vio más atrás- la Constitución es explícita con respecto al carácter de colindante de los departamentos.

¿Qué diferencia a las regiones asociativas de las actuales regiones? La libre voluntad de los asociados $\mathrm{y}$, por tanto, el carácter democrático de la región, cuando la situación se compara con la imposición tradicional hecha por el centro político nacional. En tanto las regiones son una expresión de una voluntad libremente expresada, se eliminan una serie de clivajes de las regiones actuales, que precisamente están impidiendo su funcionamiento como construcciones con contrapartida real en la historia y en la mentalidad de las personas.

\footnotetext{
15 Para citar algunos ejemplos concretos, el departamento de Antioquia en Colombia, la provincia de Valdivia en Chile, el departamento de Santa Cruz en Bolivia, el departamento de Arequipa en el Perú, son casos de regiones pivotales.
}

Los costos de transacción han resultado ser sumamente elevados en ciertos casos de conformación de regiones. La posibilidad de crear regiones asociativas permitiría reducir significativamente tales costos.

Ahora bien, las regiones pivotales o las regiones asociativas pueden hacer arreglos cooperativos tácticos con otras regiones para dar lugar a una categoría superior del ordenamiento regional: las regiones virtuales. Una región virtual es el resultado de un acuerdo contractual (formal o no) entre dos o más regiones pivotales, o bien asociativas, para alcanzar ciertos objetivos de corto y mediano plazo. ${ }^{16}$

Esto que puede sonar a fantasía ocurre en la realidad. Lo peor que puede suceder a la profesión de desarrollistas regionales es quedar, una vez más, sobrepasada por los hechos, en un rezago permanente de ideas con relación a la realidad.

En el escenario europeo, Curbelo (en prensa) afirma que: "Son ya muchas las experiencias de regiones y municipios (generalmente los de mayor tamaño) que establecen protocolos de cooperación con otras regiones y ciudades comunitarias para el desarrollo de programas conjuntos". ${ }^{17}$ En Bélgica, el programa LEDA (LIEGE-EUROPE Development/Action) tiene como propósito, entre otros, reforzar e impulsar. las alianzas entre Lieja y otras ciudades comparables en el plano internacional, a partir del lema "asociarse o morir".

La idea de una región virtual es ciertamente deudora de una modalidad de operación desarrollada por las grandes empresas transnacionales. El siguiente aviso periodístico internacional, de muy reciente data, ilustra el punto:

\footnotetext{
16 Normalmente, la introducción de una nuevo producto de alto contenido tecnológico, o la ocupación de un nicho de mercado, o la defensa de un espacio o de un territorio de negocios e influencia.

${ }^{17}$ El mismo Curbelo cita en su trabajo el ejemplo de los llamados "cuatro motores" de Europa (Ródano-Alpes de Francia, BadenWirttemberg de Alemania, Lombardía de Italia y Cataluña de España) que aúnan sus esfuerzos para el desarrollo de programas de investigación científica y tecnológica.
} 
"IBM siempre presente en los grandes avances del mundo de la computación, lanza el primer sistema basado en PowerPC. El microprocesador de más alto rendimiento en el mundo, producto de la alianza de tres grandes: IBM, Motorola y Apple. Fabricado por IBM Electronics Division."

Este es precisamente un ejemplo de una corporación virtual, un arreglo temporal para lograr un propósito determinado: competir con INTEL en el mercado de los chips de computación. Logrado el objetivo, la asociación se disuelve; en otras palabras, ninguno de los tres socios originales ha perdido su identidad corporativa.

La corporación virtual es una red temporal de compañías independientes ligadas por tecnología de información que les permite compartir habilidades, costos y acceso a los mercados de cada una de ellas. ${ }^{18}$ Los atributos claves de la asociación virtual son:

i) Tecnología. Las redes de información permitirán que compañías y empresarios alejados en distancia se unan y trabajen al unísono de principio a fin. La sociedad se basará en contratos electrónicos a fin de que no tengan que inmiscuirse los abogados y se puedan acelerar las uniones.

ii) Excelencia. Como cada socio aportaría su habilidad básica al esfuerzo, existiría la posibilidad de crear una organización que fuese la mejor en todo. Todas las funciones y procesos podrían ser de nivel mundial, algo que ninguna compañía podría lograr sola.

iii) Sentido de la oportunidad. Las sociedades serán menos permanentes, menos formales y tendrán un mejor sentido de la oportunidad. Las compañías colaborarán para aprovechar una oportunidad específica que ofrezca el mercado y, casi siempre, se disgregarán nuevamente cuando la necesidad cese.

iv) Confianza. Las compañías dependerán mucho más unas de otras y exigirán un nivel de confianza mucho más alto: compartirán un sentido de destino conjunto, ya que el destino de cada socio dependerá del otro.

v) Ausencia de fronteras: este nuevo modelo corporativo redefine las fronteras tradicionales de la compañía. La mayor cooperación entre competidores, proveedores y clientes hace difícil determinar dónde finaliza una compañía y dónde comienza la siguiente.

18 Véase el informe especial titulado "The virtual corporation" (Business Week, 1993) y el artículo de The Economist, traducido y reproducido por El Mercurio y titulado "El fin de la firma global" (El Mercurio, 1993).
El concepto de empresa-relación, parecido al anterior, se refiere a una red de alianzas estratégicas entre grandes firmas, que cubren industrias y países diferentes, pero que se mantienen unidas por metas comunes que las alientan a actuar casi como una sola firma. Tal alianza es impulsada no sólo por el cambio tecnológico, sino por la necesidad política de tener bases locales múltiples.

No se trata, por cierto, de transformar las regiones en empresas, pero es evidente que, desde el punto de vista de la gestión moderna del desarrollo regional, hay bastante que aprender de las estrategias de las grandes corporaciones. El desarrollo de los acontecimientos en el mundo empresarial avala la proposición de considerar a las regiones como cuasiempresas, es decir, como organizaciones complejas con formas de relacionamiento con el entorno que se parecen a las estrategias de desarrollo de las grandes corporaciones.

La configuración de regiones virtuales agrega a los elementos citados anteriormente otro de carácter más subjetivo, que ya fue, por lo demás, mencionado en páginas previas: la identidad. Un fuerte sentimiento de identidad regional constituye la única garantía para sostener un equilibrio en la asociación virtual e impedir que ella se transforme en una forma de absorción o de dominación. Tal identidad es el producto de una cultura regional, entendida como el conjunto de valores, símbolos y prácticas sociales (una cosmogonía y una ética) que unifica y separa simultáneamente a fin de producir la identidad. Cultura e identidad basadas en la valorización de la diversidad (algo muy propio del posmodernismo), como bien lo planteó Cerutti-Gulberg (1991) en un simposio de la Universidad de Varsovia.

Las ideas iniciales sobre virtualidad regional, que no tienen sino escasos meses de vida, han despertado considerable interés cuando han sido presentadas, presumiblemente por dos razones: por un lado, permiten superar tensiones al parecer insolubles en muchas regiones actuales construidas desde el centro abajo y, por otro, responden evidentemente a una creciente percepción de la dinámica de la globalización. ${ }^{19}$

\footnotetext{
19 A título de ejemplo, el Departamento Administrativo de Planeación del Departamento de Antioquia (Colombia), en un informe interno ("Propuesta para liderar la conformación de la región administrativa y de planificación del Occidente colombiano") afirma que: "La Región del Occidente colombiano se concibe como un proceso de alianzas estratégicas entre departamentos, con el fin de aprovechar oportunidades y asumir retos impuestos por los nuevos
} 
Al comentar las dificultades para distinguir estructuras regionales nítidas en el caso de la Argentina, Grenier (1993) señala (sic): “...el nivel más alto, en efecto, está representado por las reagrupaciones que intentan efectuar las Provincias, en este clima de competencia nacional e internacional propiciado por el neoliberalismo económico vigente desde casi dos decenios. La escala provincial estando, en tal contexto, demasiado chica, y las regionalizaciones anteriores correspondiendo a un enfoque desarrollista más bien nacional, otras fórmulas se están buscando, abiertas al exterior, como, por ejemplo, un Norte Grande abarcando los ya clásicos Noroeste Argentino y Nordeste Argentino - NOA y NEA-, e integrando, vía el GEICOS -integración del Centro Oeste del Sur de América一, a los países vecinos, Chile, Bolivia, Paraguay...".

Claramente, habría que concluir, se trata de un esfuerzo por configurar regiones virtuales. En general, los proyectos de integración fronteriza - y existen muchos programas de esa naturaleza en América Latina- son también ejemplos prácticos de la búsqueda de arreglos virtuales.

\section{IV}

\section{¿Deconstrucción regional ahora?}

Uno de los más completos argumentos a favor de la idea de construir regiones en un sentido social y político fué publicado por Boisier (1991) como culminación de un conjunto de trabajos que apuntaban a la forma de combinar elementos endógenos y elementos exógenos en el desarrollo regional.

Las regiones ahora definidas como pivotales son, por definición, regiones con un elevado nivel de autoconstrucción, sobre todo social. Sin embargo, pueden presentar carencias en su arquitectura política y administrativa, originadas en bajos estadios de descentralización político-territorial.

La construcción social y política de las regiones, como proceso esencialmente endógeno, continuará siendo un desafío en la mayoría de las regiones asociativas. ${ }^{20}$ Justamente a partir de una voluntad común explícita será más fácil diseñar y poner en ejecución un proyecto político regional, sin el cual la región no dejará de ser, por lo general, un mosaico de departamentos o de provincias.

Es importante recalcar la significación de la voluntad común de crear regiones asociativas. La "aspiración regional como movimiento social" es comen-

escenarios mundiales y nacionales". La prensa de Arequipa en el Perú, de Concepción y de Valdivia en Chile, ha recogido este tipo de propuesta con notable entusiasmo.

20 Por ejemplo, si la actual Región de la Costa Atlántica Colombiana o la actual Región del Occidente Colombiano, deciden pasar a la categoría de región de administración y de planificación, mediante el libre acuerdo de los departamentos que actualmente las configuran (o mediante otros arreglos departamentales), será necesario impulsar a fondo sus respectivos procesos de construcción. tada desde el punto de vista sociológico por Poche (1985) en los siguientes términos: "Ella hace de la reivindicación regional un movimiento social, caracterizado por una situación, la del desarrollo desigual generado por un Estado central tecnoburocrático, y por sus actores, los de una lucha social construida sobre el modelo de la lucha de clases. Habiendo sido la identidad local destruida en el proceso de desarrollo desigual, su reconquista sirve entonces de vector a esta lucha, cuya finalidad es la reconstitución de una autonomía cultural y económica sobre la base de la identidad reconstruida. La dimensión político institucional es finalmente superada en beneficio de la dimensión de sociabilidad, que la sustituye en el papel de organizador de la estructura social." (El subrayado proviene del original.)

La descentralización política, en el caso de las regiones pivotales, se convierte en una condición sine qua non, para construir hacia arriba una suerte de jerarquía "anidada" de regiones que encajan unas dentro de otras. La descentralización otorga autonomía para decidir, velocidad para actuar y recursos para la ejecución. No basta, desde este punto de vista, la mera descentralización territorial (como la existente hoy en Chile), ya que la configuración de regiones asociativas requiere de decisiones políticas endógenas, es decir, radicadas en cuerpos políticos regionales directamente elegidos por la población.

A medida que se configuran regiones asociativas a partir de una (o más de una) región pivotal, se gana en tamaño y diversidad, pero se pierde en compleji- 
dad e identidad. ${ }^{21}$ Sería posible, desde luego, pensar en una suerte de análisis marginal de costo-beneficio que permitiese decidir acerca del límite al agrandamiento de una región.

Otro asunto complejo que surge, si se piensa en la aplicación práctica de estos conceptos, es que tal vez no todas las unidades de la división políticoadministrativa vigente en un país se integren en regiones asociativas. En este caso no se configuraría un sistema nacional de regiones; se llegaría más bien a una "archipielagización" regional del territorio nacional. Si se considera que la principal utilidad de los sistemas nacionales de regiones era facilitar la desagregación regional de los planes nacionales y establecer una política nacional de desarrollo regional, dos cuestiones que quedan por completo fuera del paradigma económico vigente, la mentada "archipielagización" carece de verdadera importancia.

¿Qué estructuras - políticas y administrativasse necesitan para poner en marcha una región virtual? Puesto que el acuerdo virtual es transitorio, no puede pensarse en crear organismos estables y permanentes. Esto hace de la coordinación, más que de la dirección unificada, el eje de la cooperación. A su vez, la coordinación descansa en la comunicación; el hecho de que la tecnología actual permita la comunicación en tiempo real y cara a cara, facilita los arreglos virtuales. De nuevo, los costos de transacción pueden resultar elevados y, como apunta Alexander (1992), la planificación se hace necesaria en estos casos como parte de la respuesta a altos costos de transacción de mercado. En particular, la planificación se asocia con la jerarquización, que va desde organizaciones unitarias simples hasta marcos complejos y sistemas interorganizacionales, como serían las regiones virtuales. Cuando se desarrollan relaciones difusas y de confianza - cara a cara, según Berger y Luckmann (1968) - se reducen los costos de transacción, permitiendo el surgimiento de especializaciones flexibles, como acota Rojas (1993) en un reciente estudio preliminar sobre la debilidad de los actores sociales de la Región del Biobío, en Chile.

Hay diferentes papeles para la sociedad civil

21 A la provincia de Concepción, en Chile, que es una región pivotal, su unión con las provincias vecinas de Ñuble, Arauco y Biobío le resta complejidad y torna difusa su identidad, al punto que puede cuestionarse la utilidad colectiva de la llamada Región del Biobío. Igual predicamento podría hacerse con respecto al departamento de Antioquia o al departamento del Valle en Colombia en relación con la Región Occidente. y para la sociedad política de las regiones en la conformación de las relaciones asociativas y de las virtuales. En el primer caso, son los actores políticos los relevantes, en tanto que en el segundo son más importantes los actores civiles (empresarios y otros).

La jerarquía "anidada" de regiones pivotales, asociativas y virtuales que encajan unas dentro de otras, responde a una visión constructivista, más que positivista, de la realidad, si al menos se consideran su multiplicidad y su heterogeneidad. A ello hay que agregar que el observador/operador se incluye en la propia percepción de la realidad, única forma definitiva de salir al paso de las construcciones de arriba abajo o del centro a la periferia. Siguiendo a Edgar Morin, no hay sujeto sino en relación a un ambiente exterior, que le permite reconocerse, pensarse, existir; de esta forma se refleja mejor la complejidad, evitando el reduccionismo analítico-cartesiano que "en busca de las regularidades, redujo lo complejo a lo simple" (Montero, 1993).

La autodeterminación y la flexibilidad parecen constituir, en último término, los dos grandes ejes de la configuración de la jerarquía "anidada" de regiones pivotales, asociativas y virtuales. El paisaje resultante no puede ser percibido en términos estáticos, sino en términos dinámicos. La mejor imagen metafórica del paisaje sería una película en cámara lenta de un surtidor de agua, en la que se viera la multiplicidad y simultaneidad de estructuras que se forman y se deshacen, o la película en cámara lenta de una erupción volcánica. La autodeterminación es una cuestión de orden psicosocial y político, en tanto que la flexibilidad es una cuestión de orden técnico y administrativo.

Los arreglos virtuales tienen, además, la característica de ser múltiples, es decir, una misma región pivotal o una misma región asociativa puede mantener en forma simultánea varias ligazones virtuales, cada una de ellas conformada de manera ad hoc.

¿Por qué una nueva forma de regionalismo ahora? La respuesta es que la globalización y la emergencia de agrupaciones supranacionales como la Comunidad Europea, han producido una reacción: el deseo de los individuos de pertenecer a una comunidad más pequeña. Las nuevas tecnologías, por otro lado, hacen realidad el sueño de Schumacher - lo pequeño es hermoso- y la región, hoy, prueba ser la unidad óptima para la administración del desarrollo económico, al paso que el Estado-nación se encuentra cuestionado desde arriba y desde abajo, 
por muy pequeño o por muy grande para ocuparse de los asuntos globales, por un lado, y de los locales, por otro.

El cuadro 1 resume las principales características de los tres tipos de regiones.
¿Será ésta una propuesta de regionalización liviana, o sea, propiamente posmoderna en su liviandad? Nada de eso.

El posmodernismo de la propuesta radica en la superación de la tentación de homogeneizar, tan típica-

CUADRO 1

Regiones pivotales, asociativas y virtuales: Caracteristicas esenciales

\begin{tabular}{|c|c|c|c|}
\hline & $\begin{array}{l}\text { Región } \\
\text { pivotal }\end{array}$ & $\begin{array}{l}\text { Región } \\
\text { asociativa }\end{array}$ & $\begin{array}{l}\text { Región } \\
\text { virtual }\end{array}$ \\
\hline Configuración & Histórica & Consensuada & Contractual \\
\hline Estructura & Compleja & Heterogénea & Complementaria \\
\hline Construcción & Autoconstruida & Por construir & Selectiva \\
\hline Tipo de planificación & Estratégica & De gestión & T'áctica \\
\hline Tipo de proyecto regional & Estratégico & Político & Coyuntural \\
\hline Espacialidad & Continua & Continua & Discontinua \\
\hline Motivación societal & Autoafirmación & Poder + desarrollo & Competencia \\
\hline Temporalidad & Permanente & Largo plazo & Pactada \\
\hline Descentralización & Territorial & Territorial + política & Funcional \\
\hline Sistema de decisión ${ }^{\text {a }}$ & $\mathrm{P}$ & $\mathrm{O}+\mathrm{P}$ & $\mathrm{T}+\mathrm{O}+\mathrm{P}$ \\
\hline
\end{tabular}

a Las categorías utilizadas corresponden a las señaladas por Linstone (1987); perspectiva técnica $(T)$, perspectiva organizacional $(O)$ y perspectiva personal $(\mathrm{P})$.

mente moderna, y en la introducción de un considerable grado de flexibilidad, característica más propia del posfordismo que de la posmodernidad y, en todo caso, requisito inescapable de la contemporaneidad. "Ahora se impone la idea de la sociedad como un conjunto de flujos incontrolables, en perpetuo cambio, en medio de los cuales los actores elaboran estrategias individuales, y se aferran a identidades culturales fragmen- tarias. Es la cultura posmoderna..." (Montero, 1993).

Con independencia de las preferencias personales, los metarrelatos modernos han perdido parte de su validez y la sociedad parece regresar a ciertos fundamentalismos que se suponían superados, algunos negativos y otros no: el nacionalismo, el racismo, el sentimiento regional, los misticismos y hasta el regreso de los brujos.

\section{Bibliografía}

Alexander, E.R. (1992): A transaction cost theory of planning, Journal of the American Planning Association, vol. 58, $\mathrm{N}^{\circ}$ 2, Chicago, Ill.

Berger, P. y T. Luckmann (1968): La construcción social de la realidad, Buenos Aires, Amorrortu.

Berman, M. (1991): Todo lo sólido se desvanece en el aire, México, D.F., Siglo XXI Editores.

Boisier, S. (1976): Diseño de planes regionales, Madrid, Colegio de Ingenieros de Caminos, Canales y Puertos, Centro de Perfeccionamiento, Madrid.

(1991): Palimpsesto de las regiones como espacios socialmente construidos, S. Boisier, Territorio, Estado y sociedad, Santiago de Chile, Ed. Pehuén.

(1992): La gestión de las regiones en el nuevo orden internacional: cuasi-Estados y cuasi-empresas. Estudios Sociales. $\mathrm{N}^{\circ} 72$, Santiago de Chile, Corporación de Promoción Universitaria (CPU).

Bussiness Week (1993): The virtual corporation, $\mathbf{N}^{\circ} 3304$, Nueva York, McGraw Hill, 8 de febrero.

Caiceo, J. (1993): La antropología filosófico-cristiana de Jacques Maritain, Estudios Sociales, N$^{\circ} 78$, Santiago de Chile, CPU.
Cerutti-Gulberg H. (1991): La tradición latinoamericana de la categoría de "identidad" y su posible valor teórico futuro, Ponencia presentada al II Simposio Internacional sobre América Latina, Varsovia, Universidad de Varsovia.

Colantuono, M. R. (1991): Identidad regional neuquina, Neuquén, Argentina, Universidad Nacional del Comahue, Departamento de Geografía.

Curbelo, J.L. (en prensa): Las regiones en la transición española: del pragmatismo al aprendizaje colectivo, Revista Eure, Santiago de Chile.

Drucker, P. (1992): La sociedad postcapitalista, Buenos Aires, Editorial Sudamericana.

El Mercurio (1993): El fin de la firma global, Santiago de Chile, Empresa Editorial El Mercurio, 6 de marzo.

Germani, G. (1964): Política y sociedad en una época de transición, Buenos Aires, PAIDOS.

Grenier, P. (1993): Transformaciones regionales en Argentina desde los años sesenta, en M. Panadero, F. Cebrián y C. García (eds.) América Latina: La cuestión regional, Ciudad Real, España, Universidad de Castilla-La Mancha.

Hilhorst J. (1980): On Unresolved Issues in Regional Development 
Thinking. Occasional Papers, $\mathrm{N}^{\circ} 81$, La Haya, Países Bajos, Instituto de Estudios Sociales (ISS), abril.

Holland, S. (1976): Capital versus the Regions, Londres, The MacMillan Press.

Linstone, H. D. (1987): La necesidad de perspectivas múltiples en la planificación, Revista de la CEPAL, $\mathrm{N}^{\circ} 31$, Santiago de Chile.

Montero C. (1993) Las ciencias sociales en la sociedad postmoderna, Diario La Epoca, 7 de noviembre de 1993, Santiago de Chile.

Muller, P. (1990): Les politiques publiques, Presses Universitaires de France, París.

ODEPLAN (1968): Política de desarrollo nacional, Santiago de Chile.

Palermo, V. (1988): Neuquén: la construcción de una sociedad, Colección Estudios Argentinos, Buenos Aires.
Poche, B. (1985): ¿Une definition sociologique de la région? Cahiers internationaux de sociologie, vol. LXXIX, Grenoble.

Rojas, C. (1993): El desarrollo y la competitividad a través de la articulación de los actores sociales. Una reflexión para Concepción. Universidad del Biobío, Concepción, Chile.

SRI International (1990): Economic Success in the 1990s, Menlo Park, California.

Stohr, W. (1969): Metodología para la delimitación de regiones en Chile, en Manual de Planificación Regional, Universidad Católica de Chile/CIDU, Santiago de Chile.

Vapñarsky, C. (1969): On rank-size distribution of cities: an ecological approach, Economic Development and Cultural Change, $\mathrm{N}^{\circ} 4$, Chicago.

Vega, J.E. (1991): Entrevista en el diario La Epoca, 10 de noviembre de 1991, Santiago de Chile. 